\title{
Nutritional status and independence in instrumental activities of daily life in the elderly living in nursing homes and community dwellings: A comparative study
}

\author{
Samia Farouk Mahmoud*1, Hanady Gaber Sheha ${ }^{2}$ \\ ${ }^{1}$ Community Health Nursing Department, Faculty of Nursing, Zagazig University, Zagazig, Egypt \\ ${ }^{2}$ Fellowship of nutrition at National Nutrition Institute, Cairo, Egypt
}

Received: August 7, 2018

DOI: $10.5430 /$ jnep.v9n2p111
Accepted: September 30, $2018 \quad$ Online Published: October 25, 2018

URL: https://doi.org/10.5430/jnep.v9n2p111

\begin{abstract}
Background and objective: Dietary habits and patterns have been shown to have strong influence on the mental wellbeing of elderly. Aim of the study: to compare the current nutritional status and independence in instrumental activities of daily life (IADL) in the elderly living in nursing homes and community dwellings.

Methods: The study was carried out in nursing homes and elderly clubs in Cairo using descriptive comparative design. It involved a group of 125 institutionalized elderly from six nursing homes in Cairo and a second group (community dwellers) of 250 elderly from social clubs or elderly daycare centers in Cairo. The data collection tools were an interview questionnaire including the Mini Nutritional Assessment (MNA), the IADL, and the 24-hour recall for dietary intake in addition to an inventory checklist for the nursing homes. The data collection lasted from October 2016 to December 2017.

Results: The institutionalized elderly had significantly higher median age, more divorced /widows, from urban areas, with higher education, and more insufficient income; they were more obese $(p=.02)$. In MNA $62.0 \%$ of those in community dwellings were normal compared to only $17.6 \%$ of institutionalized $(p<.001)$, but significantly more institutionalized elders had deficient caloric intake $(80.0 \%)$ compared to $69.6 \%$ of those in community dwellings $(p=.03)$. The IADL were significantly better among those in community dwellings. In multivariate analysis, having recreations was a positive predictor of MNA score, while smoking and institutionalization were negative predictors. As for the IADL score, the level of education was its positive predictor, whereas age and institutionalization were negative predictors. Body mass index (BMI) was positively predicted by female gender, educational level, and having recreations, and negatively predicted by age. For institutionalized elderly, income was a positive predictor of the MNA score, whereas the length of institutionalization was a negative predictor.

Conclusion and recommendations: Malnutrition and dependency in IADL are more prevalent among elderly in nursing homes, and are related to the duration and characteristics of the institutionalization. The study recommends improving the dietary services in nursing homes, with training programs for their staff and regular monitoring of food services.
\end{abstract}

Key Words: Nutritional status, Elderly, Nursing homes, Mini nutritional assessment instrumental activities of daily living

\section{INTRODUCTION}

Globally, the numbers of persons aged 60 and above are expected to more than double by 2050 , and more than triple by 2100. In Africa $13 \%$ of the increase between 2015 and 2050 will occur. Life expectancy is projected to rise from 70 years in 2010-2015 to 77 years in 2045-2050 and eventually

\footnotetext{
*Correspondence: Samia Farouk Mahmoud; Email: farouk.samia@yahoo.com; Address: Community Health Nursing Department, Faculty of Nursing, Zagazig University, Zagazig, Egypt.
} 
to 83 years in $2095-2100 .^{[1]}$ Dietary habits and patterns have been shown to have strong influence on the mental wellbeing of elderly. ${ }^{[2]}$

Aging is accompanied by physiologic changes that can negatively impact nutritional status ${ }^{[3]}$ so that malnutrition is a serious problem in the elderly. ${ }^{[4]}$ It is often caused by loss or imbalance in energy, protein, vitamins and minerals intake, leading to deleterious consequences such as loss of function, disability, decreased quality of life (QoL),${ }^{[5]}$ longer hospital stays ${ }^{[6]}$ cognitive dysfunction ${ }^{[7]}$ and increased mortality. ${ }^{[8]}$ Research demonstrates that the rates of malnutrition among the elderly institutionalized in nursing homes in Finland had an increasing trend during the last decade. ${ }^{[9]}$

Furthermore, aging is also often associated with some degree of difficulty in the independent performance of Instrumental Activities of Daily Living (IADL), with a loss of autonomy, confinement, and social isolation. This is even accentuated by the high prevalence of chronic diseases among elderly, with negative effect on their quality of life, and high burden on the social and health-care systems. ${ }^{[10]}$ The loss of function in IADL often occurs in a hierarchical manner, ending in impaired performance of basic ADL, which are related to personal care. ${ }^{[11]}$ The impaired ability to move in addition to malnutrition have been associated with a higher incidence of pressure ulcers with its dreadful consequences. ${ }^{[12]}$

\subsection{Significance of the study}

The care for elderly people is provided by primary health care physicians and community health nurses. The nutritional status of elderly persons plays an important role in their functional lives and independence. It might be influenced by the setting where the elder lives whether in nursing homes or in community dwellings. Although a number of studies in different countries demonstrated differences between the two settings, ${ }^{[13,14]}$ there is a paucity of research in this area in the Egyptian context. Hence, this study is an attempt to answer the question of whether the nutritional status among elderly is different in nursing homes and community dwellings in Cairo.

\subsection{Aim of the study}

The study aim was to compare the current nutritional status and IADL in the elderly living in nursing homes and community dwellings. The research hypotheses were that institutionalization of elderly is associated with significantly lower nutritional status and less independence in the performance of IADL.

\section{SubJECTS AND METHODS}

\subsection{Research design and setting}

Descriptive comparative cross-sectional study design was used in this study, which was carried out nursing homes and elderly clubs in Cairo.

\subsection{Subjects}

The study involved two groups of elderly people aged 60 years or older. The first group (institutionalized) consisted of 125 elderly recruited from six nursing homes randomly selected from 64 nursing home providing care for elderly in Cairo; no such service is available in Zagazig, Sharkia Governorate. The selected nursing homes were Beit Al-Ailla (fifth Settlement), Honoring Egyptian Women Hotel and Dar Al-Habayeb (Maadi), Dar Om-Kalthoum, Dar El-Safa, and Dar El-Marwa. The only inclusion criterion was being institutionalized for at least three months. The second group (community dwellers) included 250 elderly recruited from social clubs or elderly daycare centers in Cairo. The exclusion criteria for both groups were having an incapacitating disease, mental or cognitive problem (scoring less than 20 in Adapted Mini Mental State Examination), or disability interfering with proper communication during interviewing.

The sample size was calculated to demonstrate an expected Odds Ratio (OR) of 2.0 or higher of low nutritional status or independence in IADLs in institutionalized elderly from a rate of $50 \%$ or less in community dwellers. Using the Open-Epi software package at $95 \%$ level of confidence and $80 \%$ study power, the required samples were 226 community dwellers and 113 institutionalized. These were increased to 250 and 125 respectively to compensate for a non-response rate of about $10 \%$. The two samples were recruited according to the eligibility criteria by convenience sampling.

\subsection{Data collection tools}

Two different tools were used for data collection namely an interview questionnaire and an inventory checklist. An additional tool was used in recruitment to fulfill the cognitive function criterion. This was the Mini Mental State Examination (MMSE). An adapted version ${ }^{[15,16]}$ was used that made the questions simple and easy to follow among illiterate elderly. All respondents who scored less than 20 were excluded.

\subsection{Interview questionnaire}

This was prepared by the researchers based on review of related literature. It included three different instruments in addition to a section for demographic characteristics such as age, gender, residence, marital status, education, past job, and income. This section also assessed elderly medical history, habits as smoking and practice of exercise, recreation 
means and pastime, etc. An additional section was for the elders in the nursing homes. It was used to solicit the characteristics of their institutionalization such as the type of room, length of stay, institutionalized by own will, reason of institutionalization, suitability of fees, and general satisfaction. It also included 11 questions about meal suitability as the number of meals, mealtimes, amount of food provided, temperature of the food, cooking, etc. Each item checked as suitable was scored one. The total meal suitability score was obtained by simple summation of the checked items so that a higher score meant more suitability.

The first measuring instrument in the interview form was the Mini Nutritional Assessment (MNA) developed by Guigoz et al. ${ }^{[17]}$ and modified by Rubenstein et al. ${ }^{[18]}$ for assessment of the nutritional status among elderly. The Full form of the MNA is administered in two steps: screening and then assessment. The screening step uses the 6-item MNA-short form (MNA-SF) dealing with appetite, weight loss, mobility, current illness, neuropsychological problems and body mass index (BMI) with maximum score 14. The elderly scoring 12 or higher is considered well-nourished, with no need to complete the assessment step. Otherwise, he/she completes the full MNA form with maximum score 30. The total score is then categorized into malnutrition $(<17)$, at-risk or susceptible (17-<24), and well-nourished (24+).

The second instrument was the IADL, ${ }^{[19]}$ which assesses the ability to perform basic functioning tasks independently. The components of this index are highly ordered allowing for gradual loss of independence in the order of ability to use the telephone, shopping, food preparation, housekeeping, laundry, transportation, medication intake, and handling own finances. Each of the functions is measured and scored according to the elderly actual performance in view of the level of ability, which ranges from 3 to 5 categories. For each function, the participant is asked to select the option that most closely resembles his/her corresponding highest functional level, either 0 or 1 . The scores of the eight items are summed-up for a total score that ranges from 0 (low function, dependent) to 8 (high function, independent). According to tool instructions, a person with a total score of 7 or higher is considered independent in IADLs, whereas a lower score is considered dependent.

The third instrument was the 24-hour recall for dietary intake. It requires respondents to remember the specific foods and the amounts consumed in the previous 24 hours. The information is then analyzed for macronutrient and micronutrient intake using computerized methods. The macronutrients were analyzed to assess the total calorie intake and protein content of the diet to ensure proper body functioning. ${ }^{[20]}$

Published by Sciedu Press
The recommended daily allowance (RDA) for calories and protein were guided by WHO. ${ }^{[21]}$

\subsection{Inventory checklist}

This was prepared by the researchers based pertinent literature to assess the nursing home characteristics. It included three sections. The first was for assessment of the management and involved items about financing, staff, facilities, regular meetings of management, services provided, etc. The second section was for the food supply and dietitian work. It covered food stuff receiving place, storage, sufficient food stuff, balanced food items, fixed meals time, providing nutritional advice, etc. The third section was for food preparation and cooking items such as convenient food receiving time, suitable kitchen space, stoves, utensils, cleaning, etc. For scoring, each item in each section checked as present was scored one. The total score of adequacy of each section was obtained by simple summation of the checked items so that a higher score meant more adequacy. Means, standard deviations, and medians were calculated.

\subsection{Validity and reliability}

Five experts from the Community Health Nursing and Medical Surgical Department, Faculty of Nursing, Zagazig University and experts from Chemical Biology, Faculty of Medicine, Zagazig University, and from National Nutrition Institute consultant reviewed the tools for face and content validation through assessing their relevance, application, comprehension, and clarity. All recommended modifications on the tools were done. The reliability of the MNA and IADL instruments was done assessed through examining their internal consistency. They had good reliability with Cronbach's Alpha coefficients 0.750 and 0.863 respectively.

\subsection{Pilot study}

A pilot study was carried out on 13 elderly nursing home residents and 25 elderly from community dwellings. It aimed at testing the applicability of the data collection tools, assessing whether the research study is feasible, and identifying any potential logistic problems. The necessary modifications were done according to the answers and comments. The subjects who shared in the pilot study were not included in the main study sample.

\subsection{Fieldwork}

Upon securing necessary official permissions, the data collection was started. After simple introduction to elders explaining the aim of the study and their rights, they were interviewed individually by the researchers who were trained in anthropometric measurements and dietary assessment. The Mini Mental State Examination was used to evaluate cog- 
nitive functioning to exclude those who score less than 20 . Weight was recorded to the nearest kilograms $(\mathrm{kg})$. Height in meters $(\mathrm{m})$ was estimated from the demi-span (distance from the tip of middle finger to midline of the sternum). The researchers continued the interview fulfilling all its sections. The time of the interview ranged from 30-40 minutes, depending on the level of understanding and cooperation of the participants.

The nursing home environment was assessed using the inventory checklist. This was done in the presence of the nursing home manager. One of the six home managers refused to allow such inventory. Hence, the results of only five homes are reported. The fieldwork was done three days weekly (Saturday, Monday and Wednesday). The process of data collection was started in October 2016 and lasted through December 2017.

\subsection{Administrative and ethical considerations}

Permissions to carry out the study were granted by submission of official letters from the Faculty of Nursing to the responsible authorities in the study settings to obtain their permission for data collection. All ethical issues were taken into consideration during all phases of the study according to the Declaration of Helsinki (DoH). As well, an oral consent was obtained from each teacher who agrees to participate in the study. They were informed that participation is voluntary and that they have the right to withdraw from the study at any time without giving any reason.

\subsection{Statistical analysis}

Data entry and statistical analysis were done using SPSS 20.0 statistical software package. Cronbach alpha coefficient was calculated to assess the reliability of the developed tools through their internal consistency. Quantitative continuous data were compared using Student $t$-test in case of comparisons between two independent groups. When normal distribution of the data could not be assumed, the non-parametric Mann-Whitney test was used. Qualitative categorical variables were compared using chi-square test. Whenever the expected values in one or more of the cells in a $2 \times 2$ tables was less than 5 , Fisher exact test was used instead. Spearman rank correlation was used for assessment of the inter-relationships among quantitative variables and ranked ones. In order to identify the independent predictors of the scores of MNA and IADL, multiple linear regression analysis was used, and analysis of variance for the full regression models done. Statistical significance was considered at $p$-value $<.05$.

114

\section{RESULTS}

Table 1 shows that the elderly institutionalized in nursing homes had significantly higher median age (72.0 years) compared to those living at home or community dwellings (65.0 years), while the gender distribution was similar with slightly more females in both. They were mostly divorced/widows, from urban areas, had higher educational level, with more professional past jobs, and more insufficient income in comparison with those living in community dwellings, and these differences were statistically significant.

As illustrated in Table 2, 34.4\% of institutionalized elderly were obese, compared to $49.2 \%$ of those in community dwellings, with lower BMI, and these differences were statistically significant $(p=.02)$. The rates of practice of exercise and smoking were low in both groups. On the other hand, the majority were having chronic diseases and were on regular medications. More community dwellings elders had their pastime with others $(82.4 \%)$ compared with institutionalized ones $(64.0 \%)$, with statistically significant difference $(p<$ $.001)$.

Concerning the nutritional status, the mini-nutritional assessment revealed that $62.0 \%$ of the elders in community dwellings were normal compared to only $17.6 \%$ of those institutionalized $(p<.001)$. As regards their dietary intakes, the majority of both groups were having normal protein intake as recommended for their age, but significantly more institutionalized elders had deficient caloric intake $(80.0 \%)$ compared to $69.6 \%$ of those in community dwellings ( $p=$ $.03)$. As for the IADL, Table 3 indicates significantly more independence in almost all activities among those living in community dwellings. In total, $31.6 \%$ were fully independent compared to only $16.8 \%$ of institutionalized ones.

The characteristics of institutionalization, Table 4 shows that the length of stay ranged between less than one to 20 years, with median 3.0 , and $69.6 \%$ of the elders were institutionalized by their own will, mostly for feeling of loneliness $(54.4 \%)$. The majority was satisfied and viewed the fees and the meals suitable.

The results of environmental assessment of the nursing homes are presented in Table 5. It indicates a high dietitian score (median 9.2 of max 11), and an average management score (median 6 of max 8). Conversely, the food preparation score was very low (median 1.0 of max 7).

Table 6 points to statistically significant small to moderate positive correlations between MNA score and elders' BMI, IADL score, and caloric and protein intake. Conversely, 
it had negative correlations with age and educational level. educational level, and having recreations, and negatively The IADL score correlated positively with caloric intake and negatively with age. Lastly, the caloric intake had a strong positive correlation with protein intake $(r=0.871)$, and a negative correlation with age.

predicted by age.

Concerning the multivariate analysis of the institutionalized elders, Table 8 demonstrates that income was a statistically significant independent positive predictor of the MNA score,

In multivariate analysis for the total sample (see Table 7), whereas the length of institutionalization was a negative prehaving recreations was the only statistically significant inde- dictor. For the IADL score, being married, exercising, and pendent positive predictor of the MNA score, while smoking and institutionalization were negative predictors. As for the IADL score, the level of education was its positive predictor, being institutionalized by own will were its positive predictors. Conversely, the negative predictors were staying in a double/triple room, the length of institutionalization, and the whereas age and institutionalization were negative predictors. meals score. Lastly, having family problems was the only Lastly, the BMI was positively predicted by female gender, significant independent negative predictor of the BMI.

Table 1. Socio-demographic characteristics of elderly in the two study groups

\begin{tabular}{|c|c|c|c|c|c|c|}
\hline & \multicolumn{4}{|l|}{ Group } & \multirow{3}{*}{$\chi^{2}$ test } & \multirow{3}{*}{$p$-value } \\
\hline & \multicolumn{2}{|c|}{ Institutionalized $(\mathrm{n}=125)$} & \multicolumn{2}{|c|}{ Home $(n=250)$} & & \\
\hline & No. & $\%$ & No. & $\%$ & & \\
\hline \multicolumn{7}{|l|}{ Age } \\
\hline $60-$ & 18 & 14.4 & 121 & 48.4 & \multirow{3}{*}{69.67} & \multirow{3}{*}{$<.001^{*}$} \\
\hline $65-$ & 25 & 20.0 & 72 & 28.8 & & \\
\hline $70+$ & 82 & 65.6 & 57 & 22.8 & & \\
\hline Range & \multicolumn{2}{|l|}{$60.0-87.0$} & \multicolumn{2}{|l|}{$55.0-89.0$} & \multirow{3}{*}{$t=72.18$} & \multirow{3}{*}{$<.001 *$} \\
\hline Mean \pm SD & $72.4 \pm 6.8$ & & $66.1 \pm 6.0$ & & & \\
\hline Median & 72.0 & & 65.0 & & & \\
\hline \multicolumn{7}{|l|}{ Gender } \\
\hline Male & 50 & 40.0 & 94 & 37.6 & \multirow[b]{2}{*}{0.20} & \multirow[t]{2}{*}{.65} \\
\hline Female & 75 & 60.0 & 156 & 62.4 & & \\
\hline \multicolumn{7}{|l|}{ Residence } \\
\hline Urban & 123 & 98.4 & 133 & 53.2 & \multirow[b]{2}{*}{78.59} & \multirow[t]{2}{*}{$<.001^{*}$} \\
\hline Rural & 2 & 1.6 & 117 & 46.8 & & \\
\hline \multicolumn{7}{|l|}{ Marital status } \\
\hline Unmarried (divorced/widow) & 109 & 87.2 & 117 & 46.8 & \multirow[b]{2}{*}{56.80} & \multirow[t]{2}{*}{$<.001^{*}$} \\
\hline Married & 16 & 12.8 & 133 & 53.2 & & \\
\hline \multicolumn{6}{|l|}{ Education } & \multirow{6}{*}{$<.001^{*}$} \\
\hline Illiterate & 7 & 5.6 & 76 & 30.4 & \multirow{5}{*}{47.08} & \\
\hline Read/write & 8 & 6.4 & 38 & 15.2 & & \\
\hline Basic & 19 & 15.2 & 32 & 12.8 & & \\
\hline Intermediate & 32 & 25.6 & 48 & 19.2 & & \\
\hline University & 59 & 47.2 & 56 & 22.4 & & \\
\hline \multicolumn{7}{|l|}{ Past job } \\
\hline None & 34 & 27.2 & 112 & 44.8 & & \multirow{4}{*}{$.002 *$} \\
\hline Clerical & 26 & 20.8 & 34 & 13.6 & & \\
\hline Manual & 31 & 24.8 & 65 & 26.0 & 15.14 & \\
\hline Professional & 34 & 27.2 & 39 & 15.6 & & \\
\hline \multicolumn{7}{|l|}{ Income } \\
\hline Insufficient & 36 & 28.8 & 34 & 13.6 & \multirow{3}{*}{15.40} & \multirow{3}{*}{$<.001^{*}$} \\
\hline Sufficient & 60 & 48.0 & 166 & 66.4 & & \\
\hline Saving & 29 & 23.2 & 50 & 20.0 & & \\
\hline
\end{tabular}


Table 2. Health and social characteristics of elderly in the two study groups

\begin{tabular}{|c|c|c|c|c|c|c|}
\hline & \multicolumn{4}{|c|}{ Group } & \multirow{3}{*}{$\chi^{2}$ test } & \multirow{3}{*}{$p$-value } \\
\hline & \multicolumn{2}{|c|}{ Institutionalized $(\mathrm{n}=125)$} & \multicolumn{2}{|c|}{ Home $(n=250)$} & & \\
\hline & No. & $\%$ & No. & $\%$ & & \\
\hline \multicolumn{7}{|l|}{ BMI } \\
\hline Normal $(<25)$ & 26 & 20.8 & 37 & 14.8 & & \\
\hline Overweight $(25-<30)$ & 56 & 44.8 & 90 & 36.0 & 7.57 & $.02 *$ \\
\hline Obese $(30+)$ & 43 & 34.4 & 123 & 49.2 & & \\
\hline Range & \multicolumn{2}{|c|}{ 20.5-50.4 } & \multicolumn{2}{|c|}{$19.9-47.8$} & & \\
\hline Mean \pm SD & \multicolumn{2}{|c|}{$29.3 \pm 5.8$} & \multicolumn{2}{|c|}{$30.4 \pm 5.6$} & $t=5.58$ & $.02 *$ \\
\hline Median & \multicolumn{2}{|c|}{28.40} & \multicolumn{2}{|c|}{29.80} & & \\
\hline Practice exercise & 48 & 38.4 & 102 & 20.8 & 0.22 & .90 \\
\hline Smoking & 11 & 8.8 & 21 & 8.4 & 0.02 & .90 \\
\hline Have chronic diseases & 115 & 92.0 & 226 & 90.4 & 0.26 & .61 \\
\hline On medications & 112 & 89.6 & 216 & 86.4 & 0.78 & .38 \\
\hline Have recreation means & 125 & 100.0 & 243 & 97.2 & Fisher & .10 \\
\hline \multicolumn{7}{|l|}{ Pastime } \\
\hline Alone & 45 & 36.0 & 44 & 17.6 & & $<.001^{*}$ \\
\hline With others & 80 & 64.0 & 206 & 82.4 & 15.59 & \\
\hline
\end{tabular}

Table 3. Nutritional status and independence in Instrumental Activities of Daily Living (IADL) of elderly in the two study groups

\begin{tabular}{|c|c|c|c|c|c|c|}
\hline & \multicolumn{4}{|c|}{ Group } & \multirow{3}{*}{$\chi^{2}$ test } & \multirow{3}{*}{$p$-value } \\
\hline & \multicolumn{2}{|c|}{ Institutionalized $(\mathrm{n}=125)$} & \multicolumn{2}{|c|}{ Home $(n=250)$} & & \\
\hline & No. & $\%$ & No. & $\%$ & & \\
\hline \multicolumn{7}{|c|}{ Mini-nutritional assessment (MNA) score } \\
\hline Malnutrition $(<17)$ & 31 & 24.8 & 12 & 4.8 & & \\
\hline Susceptible $(17-<24)$ & 72 & 57.6 & 83 & 33.2 & 75.88 & $<.001 *$ \\
\hline Normal $(24+)$ & 22 & 17.6 & 155 & 62.0 & & \\
\hline Range & \multicolumn{2}{|c|}{$9.0-29.0$} & \multicolumn{2}{|c|}{$9.0-30.0$} & & \\
\hline Mean \pm SD & \multicolumn{2}{|c|}{$20.0 \pm 4.0$} & \multicolumn{2}{|c|}{$24.6 \pm 4.0$} & $\mathrm{U}=92.29$ & $<.001 *$ \\
\hline Median & \multicolumn{2}{|c|}{20.00} & \multicolumn{2}{|c|}{25.00} & & \\
\hline \multicolumn{7}{|l|}{ Protein intake } \\
\hline Normal (RDA) & 110 & 88.0 & 225 & 90.0 & & .55 \\
\hline Deficient & 15 & 12.0 & 25 & 10.0 & 0.35 & \\
\hline \multicolumn{7}{|l|}{ Caloric intake } \\
\hline Normal (RDA) & 25 & 20.0 & 76 & 30.4 & & \\
\hline Deficient & 100 & 80.0 & 174 & 69.6 & 4.58 & $.03 *$ \\
\hline \multicolumn{7}{|l|}{ Instrumental ADL } \\
\hline Using telephone & 100 & 80.0 & 204 & 81.6 & 0.14 & .71 \\
\hline Shopping & 53 & 42.4 & 143 & 57.2 & 7.32 & $.007 *$ \\
\hline Preparing food & 38 & 30.4 & 129 & 51.6 & 15.16 & $<.001 *$ \\
\hline Housekeeping & 60 & 48.0 & 213 & 85.2 & 58.24 & $<.001 *$ \\
\hline Laundry & 40 & 32.0 & 187 & 74.8 & 63.90 & $<.001 *$ \\
\hline Transportation & 59 & 47.2 & 207 & 82.8 & 51.22 & $<.001 *$ \\
\hline Medication intake & 67 & 53.6 & 181 & 72.4 & 13.15 & $<.001 *$ \\
\hline Handle finances & 90 & 72.0 & 238 & 95.2 & 40.92 & $<.001 *$ \\
\hline \multicolumn{7}{|l|}{ Total IADL } \\
\hline Dependent & 104 & 83.2 & 171 & 68.4 & & $.002 *$ \\
\hline Independent & 21 & 16.8 & 79 & 31.6 & 9.33 & \\
\hline \multicolumn{7}{|l|}{ IADL (Lawton) score } \\
\hline Range & $0-8$ & & $0-8$ & & & $<.001^{*}$ \\
\hline Mean \pm SD & $4.1 \pm$ & & $6.0 \pm$ & & 42.14 & \\
\hline Median & 4.0 & & 6.0 & & & \\
\hline
\end{tabular}


Figure 1 presents the ecologic correlations among institutionalized elderly MNA, IADL, and meals suitability scores and the scores of institutions' characteristics. It indicates relatively good positive correlations between elderly meals scores and the institutions' dietitian and manager scores. The MNA and IADL scores do not have such correlations.

Table 4. Characteristics of nursing homes as reported by elderly in the nursing home sample $(n=125)$

\begin{tabular}{|c|c|c|}
\hline & Frequency & Percent \\
\hline \multicolumn{3}{|l|}{ Room } \\
\hline Single/suite & 108 & 86.4 \\
\hline Double/triple & 17 & 13.6 \\
\hline \multicolumn{3}{|c|}{ Length of stay (years) } \\
\hline$<1$ & 31 & 24.8 \\
\hline $1-$ & 50 & 40.0 \\
\hline $5+$ & 44 & 35.2 \\
\hline Range & $<1.0-20.0$ & \\
\hline Mean \pm SD & $4.3 \pm 4.0$ & \\
\hline Median & 3.0 & \\
\hline \multicolumn{3}{|c|}{ Institutionalized by own will } \\
\hline No & 38 & 30.4 \\
\hline Yes & 87 & 69.6 \\
\hline \multicolumn{3}{|c|}{ Reason of institutionalization } \\
\hline Loneliness & 68 & 54.4 \\
\hline Family problems & 57 & 45.6 \\
\hline \multicolumn{3}{|l|}{ Fees } \\
\hline Unsuitable & 24 & 19.2 \\
\hline Suitable & 101 & 80.8 \\
\hline \multicolumn{3}{|l|}{ Satisfied } \\
\hline No & 25 & 20.0 \\
\hline Yes & 100 & 80.0 \\
\hline \multicolumn{3}{|l|}{ Meal suitability } \\
\hline Unsuitable & 16 & 12.8 \\
\hline Suitable & 109 & 87.2 \\
\hline \multicolumn{3}{|l|}{ Score $(\max =11)$} \\
\hline Range & $2-11$ & \\
\hline Mean \pm SD & $9.7 \pm 1.8$ & \\
\hline Median & 10.0 & \\
\hline
\end{tabular}

\section{Discussion}

The current study was set to test the hypotheses that the institutionalization of elderly in nursing homes is associated with lower nutritional status and less independence in the performance of IADLs. The findings identified institutionalization as a significant independent negative predictor of the nutritional status (MNA score), as well as of the instrumental ADL score. Hence, the findings lead to acceptance of the two research hypotheses.

Table 5. Characteristics of nursing homes as observed by researchers $(n=125)$

\begin{tabular}{ll}
\hline & Frequency \\
\hline Management score $(\mathbf{m a x}=\mathbf{1 0})$ & $2-8$ \\
Range & $4.8 \pm 2.7$ \\
Mean \pm SD & 6.0 \\
Median & \\
Food supply (dietitian) score $(\mathbf{m a x}=\mathbf{1 1})$ & $8-11$ \\
Range & $9.2 \pm 1.3$ \\
Mean \pm SD & 9.2 \\
Median & \\
Food preparation (cook) score $(\max =\mathbf{7})$ & $0-7$ \\
Range & $2.6 \pm 2.9$ \\
Mean \pm SD & 1.0 \\
Median &
\end{tabular}

According to the present study results, a high proportion of the elders in both groups were females, divorced or widows, with sufficient income. The preponderance of females and widowed is expected given the higher life expectancy of women who often outlive their husbands. Meanwhile, the elderly in the nursing homes tended to be older in age, with higher educational level, and from urban areas. The difference in age is often attributed to the increasing dependency necessitating the care of a nursing home. As for the urban residence and higher educational level, they might have two explanations. The first is the dearth of nursing homes in rural areas. The second is the negative look and lack of acceptance towards nursing homes among rural people and the less educated as they still consider it a shame. Similar socio-demographic characteristics of the elderly residing in nursing homes were reported from studies in Lebanon, ${ }^{[22]}$ Syria, ${ }^{[23]}$ Finland $^{[24]}$ and Norway. ${ }^{[25]}$

Table 6. Correlation matrix of elderly BMI, MNA and IADL scores, and intake of calories and protein and their characteristics

\begin{tabular}{|c|c|c|c|c|c|}
\hline & \multicolumn{5}{|c|}{ Spearman's rank correlation coefficient } \\
\hline & BMI & MNA score & ADL score & Calories & Protein \\
\hline \multicolumn{6}{|l|}{ BMI } \\
\hline MNA score & $.167 * *$ & & & & \\
\hline IADL score & .096 & $.344^{* *}$ & & & \\
\hline Calories & .007 & $.408^{* *}$ & $.138 * *$ & & \\
\hline Protein intake & -.015 & $.380 * *$ & .089 & $.871^{* *}$ & \\
\hline Age & $-.219 * *$ & $-.334 * *$ & $-.343 * *$ & $-.107 *$ & -.075 \\
\hline Education & .089 & $-.215^{* *}$ & .031 & -.065 & -.072 \\
\hline Income & -.004 & .09 & .073 & .085 & .043 \\
\hline
\end{tabular}

${ }^{* *} p<.01 ; * p<.05$. 
Table 7. Best fitting multiple linear regression model for the mini-nutritional assessment (MNA) and activities of daily life (IADL) scores and body mass index (BMI) among all elderly

\begin{tabular}{|c|c|c|c|c|c|c|c|}
\hline & \multicolumn{2}{|c|}{ Unstandardized Coefficients } & \multirow{2}{*}{$\begin{array}{l}\text { Standardized } \\
\text { Coefficients }\end{array}$} & \multirow{2}{*}{$t$-test } & \multirow{2}{*}{$p$-value } & \multicolumn{2}{|c|}{ 95\% Confidence Interval for B } \\
\hline & B & Std. Error & & & & Lower & Upper \\
\hline \multicolumn{8}{|l|}{ MNA score } \\
\hline Constant & 9.52 & 2.76 & & 3.448 & .001 & 4.07 & 14.97 \\
\hline Institutionalization & -4.99 & 0.56 & 0.54 & 8.940 & $<.001$ & -6.09 & -3.89 \\
\hline Smoking & -1.59 & 0.81 & -0.12 & -1.963 & .051 & -3.20 & 0.01 \\
\hline Have recreations & 6.55 & 2.55 & 0.16 & 2.570 & .011 & 1.52 & 11.57 \\
\hline \multicolumn{8}{|c|}{$r$-square $=0.32 ;$ Model ANOVA: $\mathrm{F}=29.96, p<.001$} \\
\hline \multicolumn{8}{|c|}{ Variables entered and excluded: age, gender, education, marital status, income, residence, chronic diseases, exercise } \\
\hline \multicolumn{8}{|l|}{ IADL score } \\
\hline Constant & 6.42 & 2.16 & & 2.970 & .003 & 2.16 & 10.69 \\
\hline Institutionalization & -1.37 & 0.40 & 0.30 & 3.407 & .001 & -2.16 & -0.58 \\
\hline Age & -0.05 & 0.02 & -0.17 & -2.199 & .029 & -0.10 & -0.01 \\
\hline Education & 0.27 & 0.11 & 0.19 & 2.474 & .014 & 0.06 & 0.49 \\
\hline \multicolumn{8}{|c|}{$r$-square $=0.13 ;$ Model ANOVA: $\mathrm{F}=10.14, p<.001$} \\
\hline \multicolumn{8}{|c|}{ Variables entered and excluded: gender, marital status, income, smoking, residence, chronic diseases, exercise, recreation, group } \\
\hline \multicolumn{8}{|l|}{ BMI } \\
\hline Constant & 25.59 & 4.84 & & 5.283 & $<.001$ & 16.03 & 35.14 \\
\hline Female & 2.07 & 0.70 & 0.21 & 2.933 & .004 & 0.68 & 3.45 \\
\hline Age & -0.14 & 0.05 & -0.20 & -2.783 & .006 & -0.25 & -0.04 \\
\hline Education & 0.56 & 0.24 & 0.17 & 2.304 & .022 & 0.08 & 1.03 \\
\hline Have recreation & 8.60 & 3.46 & 0.18 & 2.483 & .014 & 1.77 & 15.43 \\
\hline \multicolumn{8}{|c|}{$r$-square $=0.10 ;$ Model ANOVA: $\mathrm{F}=6.04, p=.001$} \\
\hline Variables entered an & xcluded: & status, income, & oking, residen & onic & es, e & & \\
\hline
\end{tabular}

Table 8. Best fitting multiple linear regression model for the mini-nutritional assessment (MNA) and activities of daily life (IADL) scores and body mass index (BMI) among institutionalized elderly

\begin{tabular}{|c|c|c|c|c|c|c|c|}
\hline & \multicolumn{2}{|c|}{ Unstandardized Coefficients } & \multirow{2}{*}{$\begin{array}{l}\text { Standardized } \\
\text { Coefficients }\end{array}$} & \multirow{2}{*}{$t$-test } & \multirow{2}{*}{$p$-value } & \multicolumn{2}{|c|}{ 95\% Confidence Interval for B } \\
\hline & $\mathbf{B}$ & Std. Error & & & & Lower & Upper \\
\hline \multicolumn{8}{|l|}{ MNA } \\
\hline Constant & 20.58 & 0.84 & & 24.466 & $<.001$ & 18.90 & 22.26 \\
\hline Income & 1.74 & 0.60 & 0.32 & 2.879 & .006 & 0.53 & 2.95 \\
\hline Length of stay & -0.36 & 0.09 & -0.43 & -3.905 & $<.001$ & -0.55 & -0.18 \\
\hline \multicolumn{8}{|c|}{$r$-square $=0.30 ;$ Model ANOVA: $\mathrm{F}=12.19, p<.001$} \\
\hline \multicolumn{8}{|c|}{$\begin{array}{l}\text { Variables entered and excluded: age, gender, education, marital status, residence, chronic diseases, exercise, smoking, recreation, with own will, } \\
\text { cause, room type, meals, satisfaction }\end{array}$} \\
\hline \multicolumn{8}{|l|}{ IADL } \\
\hline Constant & 7.75 & 1.48 & & 5.251 & $<.001$ & 4.79 & 10.71 \\
\hline Married & 1.54 & 0.67 & 0.23 & 2.316 & .024 & 0.21 & 2.87 \\
\hline Exercising & 0.01 & 0.00 & 0.39 & 3.868 & $<.001$ & 0.00 & 0.02 \\
\hline Double/triple room & -1.91 & 0.69 & -0.26 & -2.768 & .008 & -3.30 & -0.53 \\
\hline Length of stay & -0.14 & 0.06 & -0.24 & -2.338 & .023 & -0.26 & -0.02 \\
\hline With own will & 3.75 & 0.66 & 0.58 & 5.692 & $<.001$ & 2.43 & 5.08 \\
\hline Meals score & -0.46 & 0.12 & -0.36 & -3.769 & $<.001$ & -0.70 & -0.21 \\
\hline \multicolumn{8}{|c|}{$r$-square $=0.52 ;$ Model ANOVA: $\mathrm{F}=9.70, p<.001$} \\
\hline \multicolumn{8}{|c|}{ Variables entered and excluded: age, gender, education, income, residence, chronic diseases, exercise, smoking, recreation, cause, satisfaction } \\
\hline \multicolumn{8}{|l|}{ BMI } \\
\hline Constant & 33.85 & 1.99 & & 17.037 & $<.001$ & 29.87 & 37.82 \\
\hline Family problems & -3.60 & 1.36 & -0.33 & -2.648 & .010 & -6.33 & -0.88 \\
\hline \multicolumn{8}{|c|}{$r$-square $=0.11 ;$ Model ANOVA: $\mathrm{F}=7.01, p=.010$} \\
\hline $\begin{array}{l}\text { Variables entered an } \\
\text { will, room type, mea }\end{array}$ & cluded: a & $\begin{array}{l}\text { ucation, mari } \\
\text { stay }\end{array}$ & tus, income, re & ice, chr & ic diseas & xercise, & n, with \\
\hline
\end{tabular}




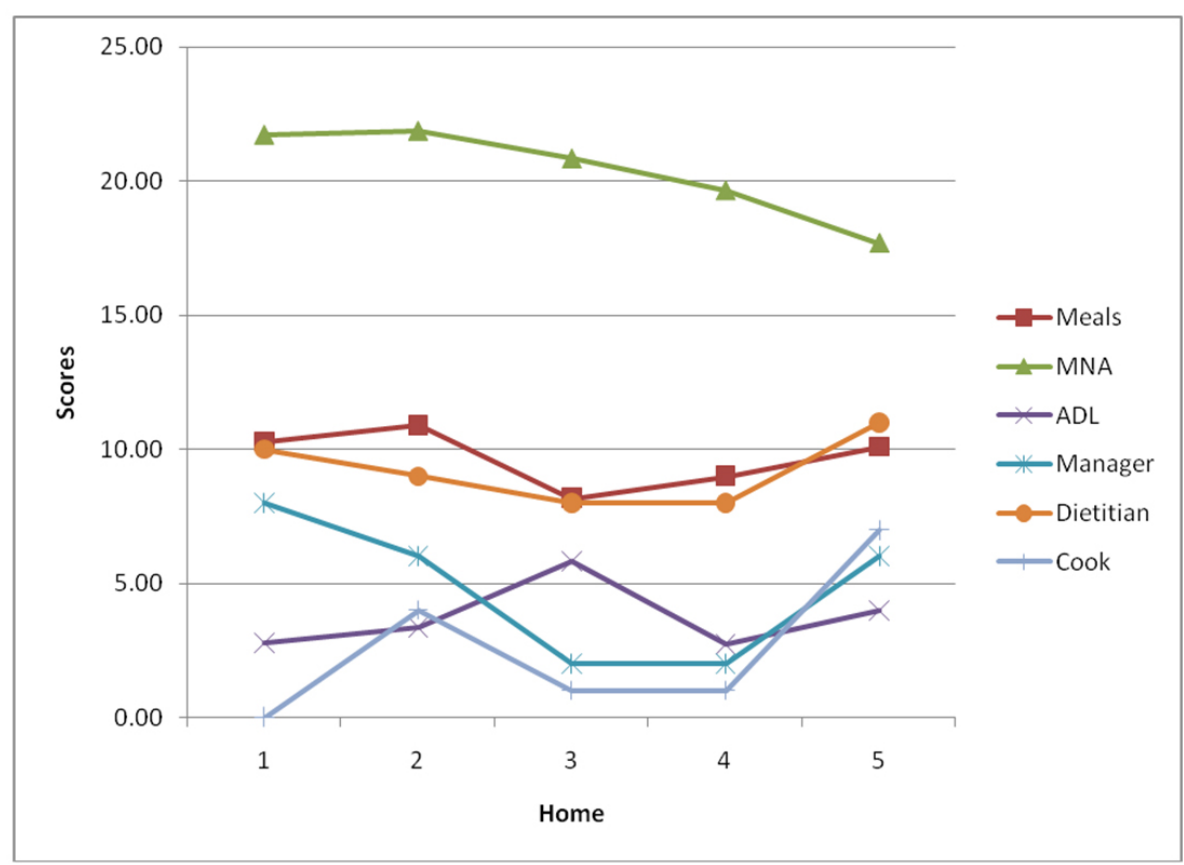

Figure 1. Ecologic correlations between institutionalized elderly BMI, MNA and IADL scores and institutions' (nursing homes) characteristics

A main objective of the current study was the assessment of the nutritional status among elderly people in nursing homes and community dwellings. The findings revealed very high prevalence of malnutrition and susceptibility to malnutrition, with around one-fourth and one-half respectively, among institutionalized elders; rates that are significantly higher compared with those in community dwellings. This could be due to their significantly lower intake of caloric requirements, although the majority of them have normal protein intake as recommended. The high percentage of elderly having their required protein intake reflects a good dietary service as reported by Keller et al. ${ }^{[26]}$ in a study in Canada.

On the same line, a study from India ${ }^{[27]}$ found that only around $13.2 \%$ of the elderly in nursing homes were wellnourished, which is close to the $17.6 \%$ in the current study. Similar high rates of malnourished and susceptible to malnutrition were reported from studies in Brazil ${ }^{[28]}$ and Turkey. ${ }^{[29]}$ Meanwhile, a higher rate of malnourished in Egyptian elders in community dwellings (14.5\%) was reported by Abdelrahman and Elawam, ${ }^{[30]}$ and this was linked to older age, less education, and living alone.

Concerning the nutritional status of the elderly living in community dwellings, the present study results indicated that only $4.8 \%$ of them were having malnutrition, which is in congruence the results of a study in Australia. ${ }^{[31]}$ Moreover, the mean MNA score among the elderly in community dwellings in the current study was $24.6 \pm 4.0$, which is very close to the figure reported by Han et al. ${ }^{[32]}$ in China, where the mean MNA score was $23.8 \pm 3.92$.

The significantly lower nutritional status demonstrated among the present study elders institutionalized in nursing homes was shown to be independently predicted by their being institutionalized. Moreover, the length of stay in the nursing home was negatively related to their nutritional status. Hence, it might be explained not only by diet and nutritional intake, but also by other non-dietary factors such as the family and nursing home-related elements. In fact, the multivariate analysis demonstrated that income was a positive predictor of the MNA score, which could be attributed to the higher ability of the wealthier elder person to purchase the food he/she likes. Similar effects of institutionalization on the elderly nutritional status were reported in studies in Australia $^{[31]}$ and in Iran. ${ }^{[33]}$

In the present study, the majority of the elderly persons in the two groups were either overweight or obese. However, the institutionalized ones tended to be significantly less obese, and had lower BMI. The high prevalence of overweight/obesity is consistent with the corresponding high rates in the general population in Egypt, particularly with its association with female gender ${ }^{[34,35]}$ Meanwhile, the lower BMI among institutionalized ones could be attributed to their generally older age, and lower physical and psychological health status compared with those living at home in community dwellings. In fact, the multivariate analysis showed that BMI was neg- 
atively predicted by age and family problems. Conversely, it was positively related to the educational level and having recreations. Similarly high rates of overweight and obesity was reported among Portuguese elderly, with significantly higher rates among women. ${ }^{[36]}$ Moreover, another study in Portugal reported significant associations between high socioeconomic level parameters and BMI in elderly. ${ }^{[37]}$

The present study has also compared the independence in the performance of IADLs among elderly in nursing homes and in community dwellings. The findings revealed that those institutionalized in nursing homes were significantly more dependent in their IADLs, and this was confirmed in multivariate analysis. This difference could have two different explanations. The first is that the high dependence in IADLs could be one of the reasons of institutionalization The second could be the effect of institutionalization on elders' activities, which might be restricted by the nursing home rules and regulations, in addition to the availability of help all the time, which might increase their dependence. In agreement with this, a large national Korean study demonstrated a high level of dependency among institutionalized elderly, and this was associated with malnutrition assessed by MNA. ${ }^{[38]}$

In addition to the effect of institutionalization on elders' IADL, older age had also a negative influence as expected. On the other hand, other characteristics indicating better socioeconomic status as the level of education, being married, exercising regularly, having recreation activities, and being institutionalized by own will had a positive impact on their IADLs. This might be attributed to a better health awareness and behavior among them. In congruence with this, a study in the United States revealed significant associations between diverse social and health-related activities and elders' independence in IADLs. ${ }^{[39]}$ On the same line, the rates of independence in IADLs tend to be high in developed countries such as in Norway where Boulos et al. ${ }^{[25]}$ reported that $61.7 \%$ of the elderly were fully independent. Conversely, the rates are low in developing countries such as in Turkey, ${ }^{[29]}$ where the rate was $25.3 \%$, close to the rates in the present study.

The present study findings revealed a significant positive correlation between elders' scores of MNA and IADL. This is quite plausible given the positive effect of good nutrition on the ability to function and move properly. In agreement with this, Pereira et al. (2015) in Brazil demonstrated the presence of a statistically significant correlation between MNA and IADL scores. However, this relation between MNA and IADL was not confirmed in the multivariate analysis of the current study. This might be due to that the ability to perform IADLs independently is multifactorial, and depends on several causes and considerations.

Lastly, regarding the effects of nursing home administration and its characteristics related to nutrition of residents, the current study ecologic analysis revealed positive correlations between the scores related to dietitian role and management and elders' scores of satisfaction with meals. This reflects their high satisfaction with institutionalization. Such assessment of nursing homes is required to check the quality of the services provided. ${ }^{[40]}$

However, the MNA and IADL scores were not significantly correlated to any of the three nursing homes' scores in the present study. This could be due to the fact that the MNA and IADL scores are influenced by multiple factors, including elder personal characteristics. The nursing home staff awareness of elderly people dietary requirements is another important factor as emphasized by Lea et al..$^{[41]}$ in a study in Australia. It could also be due to the bias of ecologic fallacy inherent in this type of analysis. Hence, the issue needs further study.

\section{CONCLUSION AND RECOMMENDATIONS}

In conclusion, malnutrition and dependency in IADL are more prevalent among elders institutionalized in nursing homes compared to those in community dwellings, and they are related to the duration and characteristics of the institutionalization. The study recommends improving the dietary services in nursing homes, with training programs for their staff and regular monitoring of their food services. Regular checkup of elderly nutritional status using the MNA tool could help in early detection and prompt management of malnutrition. Further research is proposed to examine the effects of these interventions on elderly people physical and psychological health status.

\section{CONFLICTS OF INTEREST Disclosure}

The authors declare that there is no conflict of interest.

\section{REFERENCES}

[1] United Nations, Department of Economic and Social Affairs, Population Division. World population ageing 2015.ST/ESA/SER.A/348. 2013. Available from: http: //www.un.org/en/development/desa/population/public
ations/pdf/ageing/WorldPopulationAgeing2013.pdf

[2] Pagliai G, Sofi F, Vannetti F, et al. Mediterranean Diet, Food Consumption and Risk of Late-Life Depression: The Mugello Study. J Nutr Health Aging. 2018; 22(5): 569-574. PMid:29717755 https : //doi.org/10.1007/s12603-018-1019-3 
[3] Saikia AM, Mahanta N. A Study of Nutritional Status of Elderly in Terms of Body Mass Index in Urban Slums of Guwahati City. Journal of the Indian Academy of Geriatrics. 2013; 9: 11-14.

[4] Waitzberg DL, De Aguilar-Nascimento JE, Dias MCG, et al. Hospital and homecare malnutrition and nutritional therapy in Brazil. Strategies for alleviating it: a position paper. Nutr Hosp. 2017; 34(4): 969-975.

[5] Nykänen I, Lönnroos E, Kautiainen H, et al. Nutritional screening in a population-based cohort of community-dwelling older people. Eur J Public Health. 2013; 23: 405-9. PMid:22539629 https://doi.org/10.1093/eurpub/cks026

[6] Verbrugghe M, Beeckman D, Van Hecke A, et al. Malnutrition and associated factors in nursing home residents: A cross-sectional, multi-centre study. Clin Nutr. 2013; 32: 438-43. PMid:23089280 https://doi.org/10.1016/j.clnu.2012.09.008

[7] Rosted E, Prokofieva T, Sanders S, et al. Serious Consequences of Malnutrition and Delirium in Frail Older Patients. J Nutr Gerontol Geriatr. 2018 May 24; 1-12.

[8] Söderström L, Rosenblad A, Adolfsson ET, et al. Nutritional status predicts preterm death in older people: a prospective cohort study. Clinical Nutrition. 2013

[9] Saarela RKT, Muurinen S, Suominen MH, et al. Changes in malnutrition and quality of nutritional care among aged residents in all nursing homes and assisted living facilities in Helsinki 20032011. Arch Gerontol Geriatr. 2017; 72: 169-173. PMid:28672199 https://doi.org/10.1016/j.archger.2017.06.008

[10] Andrade FCD, Guevara PE, Lebrao ML. Gender differences in life expectancy and disability-free life expectancy among older adults in Sao Paulo, Brazil. Womens Health Issues. 2011; 21: 6470. PMid:21185991 https://doi.org/10.1016/j . whi.2010.0 8.007

[11] Corona LP, de Brito BRP, Nunes DP, et al. Nutritional status and risk for disability in instrumental activities of daily living in older Brazilians. Public Health Nutrition. 2012; 1-6.

[12] Lavallée JF, Gray TA, Dumville J, et al. Barriers and facilitators to preventing pressure ulcers in nursing home residents: A qualitative analysis informed by the Theoretical Domains Framework. Int J Nurs Stud. 2018; 82: 79-89. PMid:29626701 https: //doi.org/10.1016/j.ijnurstu.2017.12.015

[13] De Lima CBV, Moraes FL, Cristine Souza LA. Nutritional Status and Associated Factors in Institutionalized Elderly. J Nutr Disorders. 2012; 2: 116.

[14] Strathmann S, Lesser S, Bai-Habelski J, et al. Institutional factors associated with the nutritional status of residents from 10 german nursing homes (ernstes study). The Journal of Nutrition, Health \& Aging. 2013; 17(3): 271-276. PMid:23459981 https: //doi.org/10.1007/s12603-012-0410-8

[15] Folstein MF, Folstein SE, McHugh PR. "Mini-mental state": a practical method for grading the cognitive state of patients for the clinician. J Psychiatr Res. 1975; 12: 189-198.

[16] Crum RM, Anthony JC, Bassett SS, et al. Population-based norms for the mini-mental state examination by age and educational level. JAMA. 1993; 269(18): 2386-2391. https://doi .org/10.1001/ jama.1993.03500180078038

[17] Guigoz Y, Vellas B, Garry PJ. Assessing the nutritional status of the elderly: The Mini Nutritional Assessment as part of the geriatric evaluation. Nutr Rev. 1996; 54(1 Pt 2): S59-65.

[18] Rubenstein LZ, Harker JO, Salva A, et al. Screening for Undernutrition in Geriatric Practice: Developing the Short-Form Mini Nutritional Assessment (MNA-SF). J. Geront. 2001; 56A: M366-377.
[19] Lawton MP, Brody EM. Assessment of older people: Selfmaintaining and instrumental activities of daily living. Gerontologist. 1969; 9: 179-186.

[20] Mahan KL, Escott-Stump S, Raymond JL. Krause's Food and the nutrition care process; Saunders an imprint of Elsevier Inc. 2012.

[21] WHO. Nutrition for old persons. 2018. Available from: http://ww w. who.int/nutrition/topics/ageing/en/index1.html

[22] Doumit JH, Nasser RN, Hanna DR. Nutritional and health status among nursing home residents in Lebanon: comparison across gender in a national cross sectional study. BMC Public Health. 2014; 14(1): 2-11.

[23] Hallaj FA. Assessment of the nutritional status of residents in homes for the elderly in Lattakia, Syrian Arab Republic. Eastern Medoterranean Health Journal. 2015; 21(10): 753-761. https: //doi.org/10.26719/2015.21.10.753

[24] Jyväkorpi S. Nutrition of older people and the effect of nutritional interventions on nutrient intake, diet quality and quality of life. Department of General Practice and Primary Health Care Faculty of Medicine University of Helsinki Finland. 2016.

[25] Boulos C, Adib SM, Mitri R, et al. Nutritional Status of the Elderly in an Arab Country in Social Transition: the Case of Lebanon. Springer International Publishing. V.R. Preedy, V.B. Patel (eds.), Handbook of Famine, Starvation, and Nutrient Deprivation. 2017.

[26] Keller HH, Carrier N, Slaughter SE, et al. Prevalence and Determinants of Poor Food Intake of Residents Living in Long-Term Care. J Am Med Dir Assoc. 2017; 18(11): 941-947. PMid:28668663 https://doi.org/10.1016/j.jamda.2017.05.003

[27] Kavya C, Santosh A. Geriatric health: assessment of nutritional status and functional ability of elderly living in rural area of Bangalore, Karnataka, India. Int J Community Med Public Health. 2016; 3(12): 3460-3464

[28] Pereira AS, Luiza M, de Almeida M, et al. Nutritional status of institutionalized elderly Brazilians: a study with the Mini Nutritional Assessment Nutrición Hospitalaria. 2015; 31(3): 1198-1204.

[29] Kucuk EO, Kapucu S, Dergisi KT. Malnutrition elderly in nursing homes. Hacettepe University Faculty of Nursing, Sihhiye. 2017; 9(3): 46-51.

[30] Abdelrahman HMM, Elawam AEE. Nutrition Status in Community Dwelling Older Population in an Egyptian Urban Area. Ain Shams University, Faculty of Medicine, Geriatric Department, Cairo, Egypt. Journal of Aging Research \& Clinical Practice. 2014; 3(3).

[31] Luger E, Haider Aider S, Kapan A, et al. Association between nutritional status and quality of life in frail communing dwelling older persons. The Journal of Frailty \& Aging. 2016; 5(3): 141-148.

[32] Han Y, Li S, Zheng Y. Predictors of nutritional status among community-dwelling older adults in Wuhan, China. Public Health Nutrition Journal. 2009; 12(8): 1189-1196. PMid:18789169 https : //doi.org/10.1017/S1368980008003686

[33] Abolghasem Gorji H, Alikhani M, Mohseni M, et al. The Prevalence of Malnutrition in Iranian Elderly: A Review Article. Iran J Public Health. 2017; 46(12): 1603-1610.

[34] Mowafi M, Khadr Z, Kawachi I, et al. Socioeconomic status and obesity in Cairo, Egypt: a heavy burden for all. J Epidemiol Glob Health. 2014; 4(1): 13-21. PMid:24534331 https ://doi .org/10 $.1016 / j \cdot j$ jegh. 2013.09.001

[35] Abdel Wahed WY, Hassan SK, Eldessouki R. Malnutrition and Its Associated Factors among Rural School Children in Fayoum Governorate, Egypt. J Environ Public Health. 2017.

[36] Silveira EA, Vieira LL, Souza JD. High prevalence of abdominal obesity among the elderly and its association with diabetes, hypertension and respiratory diseases. Cien Saude Colet. 2018; 23(3): 903-912. 
[37] Silva VSD, Souza I, Silva DAS, et al. Trends and association of BMI between sociodemographic and living conditions variables in the Brazilian elderly: 2002/03-2008/09. Cien Saude Colet. 2018; 23(3): 891-901.

[38] Park M, Song JA, Lee M, et al. National study of the nutritional status of Korean older adults with dementia who are living in long-term care settings. Jpn J Nurs Sci. 2018 Jan 17.

[39] Chase JD, Hirschman KB, Hanlon AL, et al. Physical Functioning Among Older Adults New to Long-Term Services and Supports.
Gerontologist. 2017 May 25.

[40] Delaney CM, Rafalson L, Fiedler RC, et al. Quality indicator survey versus traditional survey in New York State: a comparison of results from annual nursing home surveys. J Aging Soc Policy. 2018; 30(2): 127-140. PMid:29279014 https://doi .org/10.1080/08 959420.2017.1406838

[41] Lea EJ, Goldberg LR, Price AD, et al. Staff awareness of food and fluid care needs for older people with dementia in residential care: A qualitative study. J Clin Nurs. 2017; 26(23-24): 5169-5178. 